\title{
Cephalometric Evaluation of the Airway Space and Hyoid Bone in Children with Atypical Deglutition: Correlations Study
}

\author{
Evaluación Cefalométrica del Espacio de las Vías Respiratorias \\ y Hueso Hioides en Niños con Deglución Atípica: Estudio Correlacional
}

*Almiro J. Machado Júnior \& **Agrício N. Crespo

MACHADO JÚNIOR, A. J. \& CRESPO, A. N. Cephalometric evaluation of the airway space and hyoid bone in children with atypical deglutition: correlations study. Int. J. Morphol., 30(1):341-346, 2012.

SUMMARY: Although there is a close relationship between swallowing and breathing are no studies that relate to atypical swallowing radiographic anatomy of the airway space and its possible correlation with the radiographic position of the hyoid bone. The aim was to evaluate the possible correlation with the radiographic position of the hyoid bone and airway space in lateral radiographs of children with atypical deglutition. Using cephalometric analysis on lateral teleradiographs, the distances of H-MP (hyoid to mandibular plane) and H-T (hyoid to tuber) were Spearman's correlation analysis was performed with PAS (airway space) in two groups: the experimental group with atypical deglutition and the control group normal deglutition. Both groups included subjects in mixed dentition stage. The variable T-H had statistically significant correlation with PAS (0.0286) and the variable MP-H had significant correlation with variable PAS (0.0053). Our results show that advanced positive correlation of the radiographic position of the hyoid bone to the airway space only in the group of normal swallowing. The lower airway in patients with atypical swallowing, causing changes in tongue posture which leads to change in the position of the hyoid bone.

KEY WORDS: Cephalometry; Atypical deglutition; Oropharyngeal space.

\section{INTRODUCTION}

Although swallowing is the first function to be established in the stomatognathic system, it is the last process to mature, because while the bone structures are growing and dentition does not take place, the tongue cannot acquire mature posture and movement. Only when the child is around two years of age, a pattern of transitory (inconstant) swallowing to the mature pattern - called somatic swallowing - is expected, with the tongue on the limits of the dental arcade, with the soft tissues more adjusted and the lips sealed. A visceral type of swallow can persist well after the fourth year of life. However, it is then considered as a dysfunction or abnormality because of its association with certain dental malocclusions and facial growing alterations (Peng et al., 2003; Graber et al., 1985). Such deglutition is classified as atypical (Peng et al., 2004; Ovsenik et al., 2007; Bertolini et al., 2003).

Current studies have investigated the swallowing pattern in child development and have concluded that atypical swallowing has been present in half of the children examined at age three, has changed significantly after age six but has still been present in 25 per cent at age twelve (Ovsenik et al.). The movements of the tongue during swallowing may be clinically assessed, asking the child to swallow liquids, semi-solids or solids or even only saliva to observe the protrusion of the tongue with the lips half-open or, if necessary, with lips opened with the fingers (forced opening method) (Peng et al., 2003, 2004). By placing the hands on the masseters it is possible to observe the presence or absence of contraction and to observe the ascendant movement of the hyoid bone under the thyroid cartilage. The participation of the perioral muscles is also observed, as well as whether the swallowing is loud, if there is a retraction movement with the head, the presence of any signal which characterizes child swallowing (Peng et al., 2003, 2004; Ovsenik et al.; Bertolini et al.). For a variety of reasons that so far remain incompletely explained, 'infantile swallowing' may continue beyond the replacement of the deciduous teeth. Atypical deglutition has been attributed to sucking without nutritive purposes, use of feeding bottles, oral respiration,

\footnotetext{
* Dental surgeon and doctoral student in Medical Sciences, Discipline of Otorhinolaryngology, School of Medical Sciences, State University of Campinas (Unicamp), Brazil.

** Otorhinolaryngologist, Full Professor, Head of the Discipline of Otorhinolaryngology, School of Medical Sciences, State University of Campinas (Unicamp), Brazil. Part of Doctoral Thesis, Discipline of Otorhinolaryngology, School of Medical Sciences, State University of Campinas (Unicamp), Brazil.
} 
abnormalities of the central nervous system, and anatomical abnormalities (Bertolini et al.; Cayley et al., 2000; Cheng et al., 2002). However, there is no consensus regarding the etiology of atypical deglutition (Machado Júnior \& Crespo, 2012a; de Felício et al., 2010; Valera et al., 2003).

Synchronization of sucking and swallowing is a close relationship between the muscles of the oral region for generating suction pressure for opening and closing your mandible and tongue to bolus formation and its peristaltic transport to the pharynx (Valera et al.). During oral feeding, the mechanical respiration involves the proper activation of the diaphragm, intercostal muscles and the muscles of the upper airways of the nose to the glottis (Valera et al.). Among the likely anatomical abnormalities in cases of atypical deglutition is the position of the hyoid bone, since this is the origin or insertion point of several muscles relating to deglutition (Adamidis \& Spyropoulos, 1983; Cheng et al., 1988; Paskay, 2006).

Recent studies have evaluated airway space and hyoid bone position in month breathing and obstructive sleep apnea (OSA) (Malkoc et al., 2005; Machado Júnior \& Crespo, 2010; Kikyo et al., 1999; Bibby, 1984). Although there is a close relationship between swallowing and breathing are no studies that relate to atypical swallowing radiographic anatomy of the airway space and its possible correlation with the radiographic position of the hyoid bone. The objective of this study was to evaluate the possible correlation with the radiographic position of the hyoid bone and airway space in lateral radiographs of children with atypical deglutition.

\section{MATERIAL AND METHOD}

The research protocol of this study received unrestricted prior approval from the Research Ethics Committee. This was a observational study in which lateral teleradiographs from children of both sexes at the phase of mixed dentition were evaluated. The whole study sample consisted of 110 teleradiographs in lateral view, from 52 female and 58 male subjects. The two groups were similar with regard to gender distribution. The mean age of the control group (normal deglutition) and the experimental group was 9.46 years and 10.05 years, respectively. To define the control and experimental groups an initial test forced opening method was conducted (Peng et al., 2003, 2004; Graber et al.) by three senior orthodontists simultaneously, defining by consensus to which group the teleradiography of the child should belong. The sample size was determined to obtain the appropriate power level. Twenty lateral teleradiographs of 20 patients with a clinical diagnosis of atypical deglutition and another 20 la- teral teleradiographs of 20 subjects with normal deglutition were selected for a pilot study to calculate the sample size in which the standard deviation of the control group and the difference between the means of the control and experimental groups were calculated. At a significance level of $0.05,110$ teleradiographs (i.e. 55 in each group) were required to achieve a test power of 0.10 . After sample size estimation, the whole sample was selected using the same criteria employed in the pilot study, as described above.

All lateral view teleradiographs selected for the present study sized $18 \mathrm{~cm}$ x $24 \mathrm{~cm}$, and were obtained using the same Siemens apparatus in one second at $6 \mathrm{kVp}$ with a focal length of 1.5 meters. The examinations were performed with the patient's head in a natural position (mirror position), performed by the same examiner. Using the selected lateral teleradiographs, cephalometric examination was performed in a darkened room with a negatoscope. An acetate sheet was laidover the teleradiograph and the following anatomoradiographic points and planes were marked on the sheet (Fig. 1): T-H: tuber (line of intersection between the center of the pterygomaxillary fissure and the posterior nasal spine) to hyoid (most anterosuperior point of the body of the hyoid bone); MP-H: mandibular plane (line from the midpoint of the mandibular angle to the lowest point on the outline of the mentonian symphysis) to hyoid; PAS: frontal wall of pharyngeal airway to posterior wall of pharyngeal airway.

Lateral teleradiographs that did not provide a good view of the anatomical structures used in the cephalometric examination were excluded from the study sample. Patients with dental agenesis, congenital poor orofacial formation, orthodontic and/or functional orthopedic treatment prior to the study, or doubts and imprecision regarding the diagnosis of deglutition were also excluded. A lack of unanimity among the examiners on the clinical diagnosis was also a factor of exclusion of the sample. The skeletal pattern and maloclusion of the patients were not taken into consideration in this study.

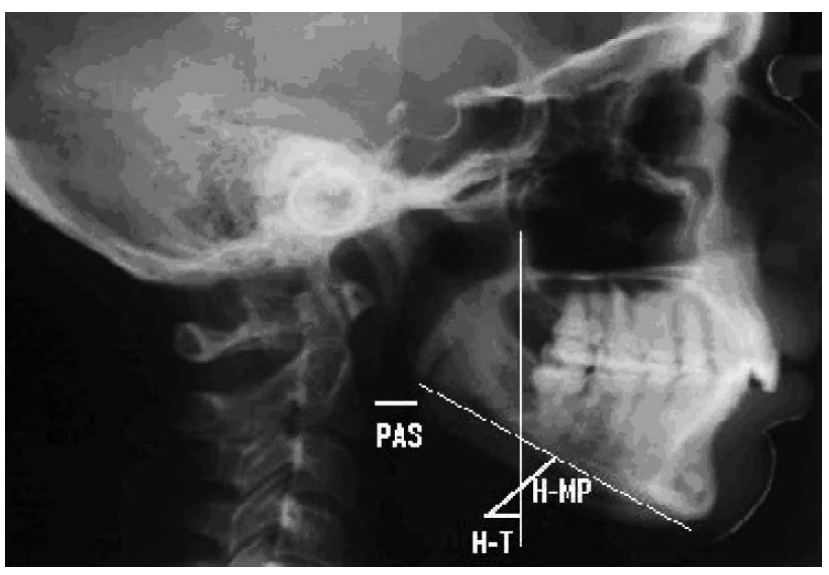

Fig. 1. Cephalometric measurements. 
The lateral teleradiographs from the experimental group and the control group were randomly put aside and numbered sequentially. The examiner performing the manual measurements were blinded to patient data. The sequentially numbered teleradiographs were handed over to the examiner for the standardized abovementioned measurements to be made, and measurement results were recorded to a data collection instrument. To minimize systematic errors, the same examiner carried out data collection of the whole sample on two occasions separated by a 20-day interval. After the collection of radiographic data, age and sex data were added, along with whether atypical deglutition was present or not. On the other hand, all appropriate measures were taken to ensure confidentiality of the subjects' personal data. Only the initials were recorded to the data collection instrument. There was no way in which persons other than the investigator would be able to identify the individual to whom each teleradiograph belonged.

To investigate a possible linear association (correlations) between of variables H-MP, H-T and PAS, Spearman's correlation analysis was performed. To investigate the intra-examiner consistency, Wilcoxon test for related samples was used to detect possible differences between measurements obtained in two different occasions. The significance level used in the statistical tests was $\mathrm{P}=0.05$.

Table I. Comparative analysis of the variable male and female subjects.

\begin{tabular}{cccc}
\hline Deglutition & male & female & p-value \\
\hline Normal & 33 & 22 & 0.1266 \\
Atypical & 25 & 30 & \\
\hline
\end{tabular}

\section{RESULTS}

The whole study sample consisted of 110 teleradiographs in lateral view, from 52 female and 58 male subjects. The two groups were similar with regard to gender distribution (Table I). The mean age of the control group (normal deglutition) and the experimental group was 9.46 years and 10.05 years, respectively, without any significant difference between the groups (Table II). To investigate the intra-examiner consistency, Wilcoxon test for related samples was used to detect possible differences between measurements obtained in two different occasions. However, no significant difference was found between these two measurements (Machado Júnior \& Crespo, 2012a). MannWhitney U test was used to compare the two groups with regard to cephalometric measurements. The average distance of the MP-H variable was 11.69 millimeters for the control group and 16.14 millimeters for the experimental group, with a statistically significant difference $(\mathrm{p}=0.016)$ (Table III). The average distance of the $\mathrm{T}-\mathrm{H}$ variable was 2.26 millimeters for the control group and -5.89 millimeters for the experimental group, with significant difference $(\mathrm{p}<0.001)$ (Table IV). There was no correlation among the variables MP-H and T-H. The average distance of the PAS variable was $7 \mathrm{~mm}$ in the experimental group and was $10 \mathrm{~mm}$ in the control group, with a statistically significant difference ( $\mathrm{p}$ $<0.001$ ) (Table V) (Machado Júnior \& Crespo, 2012b). There is a positive correlation between MP-H and PAS ( $\mathrm{p}=0.0053$ ) and T-H and PAS ( $\mathrm{p}=0.0286)$ variables. These correlations were only observed in the control group (Table VI).

Table II. Comparative analysis of the variable age.

\begin{tabular}{cccccccc}
\hline Deglutition & $\mathrm{n}$ & Mean & $\begin{array}{c}\text { Standard } \\
\text { deviation }\end{array}$ & Minimum & Median & Maximum & $\begin{array}{c}p \text {-value } \\
\text { Mann-Whitney }\end{array}$ \\
\hline Normal & 55 & 9.32 & 1.83 & 6.41 & 9.25 & 11.66 & 0.6345 \\
Atypical & 55 & 9.58 & 2.13 & 6.41 & 9.08 & 11.91 & \\
\hline
\end{tabular}

Table III. Comparative analysis of the variable MP-H (mm)

\begin{tabular}{lccccccc}
\hline Deglutition & $\mathrm{n}$ & Mean & $\begin{array}{c}\text { Standard } \\
\text { deviation }\end{array}$ & Minimum & Median & Maximum & $\begin{array}{c}\text { p-value } \\
\text { Mann-Whitney }\end{array}$ \\
\hline Normal & 55 & 11.69 & 5.13 & 3.00 & 12.00 & 21.00 & 0.016 \\
Atypical & 55 & 16.14 & 4.86 & 7.00 & 16.00 & 27.00 & \\
\hline
\end{tabular}

Table IV. Comparative analysis of the variable T-H (mm)

\begin{tabular}{lccccccc}
\hline Deglutition & $\mathrm{n}$ & Mean & $\begin{array}{c}\text { Standard } \\
\text { deviation }\end{array}$ & Minimum & Median & Maximum & $\begin{array}{c}\text { p-value } \\
\text { Mann-Whitney }\end{array}$ \\
\hline Normal & 55 & 2.26 & 1.79 & 0.00 & 2.00 & 6.00 & $<0.001$ \\
Atypical & 55 & -5.89 & 4.77 & -16.00 & -5.00 & 4.00 & \\
\hline
\end{tabular}


Table V. Comparative analysis of the variable PAS (mm).

\begin{tabular}{cccccccc}
\hline Deglutition & $\mathrm{n}$ & Mean & Standard deviation & Minimum & Median & Maximum & $\begin{array}{c}\text { p-value } \\
\text { Mann-Whitney }\end{array}$ \\
\hline Normal & 55 & 10.53 & 2.43 & 5.00 & 10.00 & 15.00 & $<0.001$ \\
Atypical & 55 & 7.82 & 2.93 & 3.00 & 7.00 & 13.00 & \\
\hline
\end{tabular}

Table 6. Coefficients of linear Spearman's correlation between variables in each group.

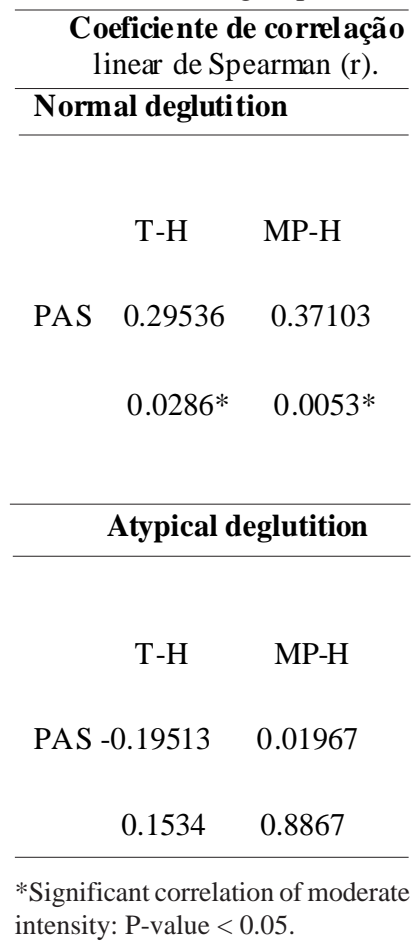

\section{DISCUSSION}

Interest in further study of atypical deglutition continues due to many gaps in the literature on this topic. Appealing study topics include the expansion of the classifications of deglutition (Peng et al., 2004; Ovsenik et al.; Bertolini et al.); the causes of atypical deglutition and its consequences (Cheng et al., 2002); diagnostic methods (Cayley et al.; Bibby) age at its onset, and treatment methods.

Deglutition is a highly complex and coordinated function, requiring activation of many anatomical structures related to the tongue. Insufficient functional stimulation of the stomatognathic system, especially the tongue, may evolve as the main factor linked to the persistence of childlike/ infantile patterns of deglutition.
A variety of instrumental techniques are available for diagnosing atypical deglutition. Prominent among the methods that have been used for diagnosis during the oral phase of deglutition is videofluoroscopy. This instrumentation has limited availability in dental practice since the equipment is usually a part of hospital-based radiology departments. The evaluation of the images obtained by videofluoroscopy involves rather subjective assessments (Cayley et al.; Bibby; Peng et al., 2004) however, the multiple views of swallows, involving the frontal, lateral, and coronal dimensions, provide useful descriptions of the mechanical properties of deglutition.

Teleradiographs are standardized extraoral images that are routinely used as an orthodontic/orthopedic functional diagnostic tool (Kikyo et al.). Teleradiography has been used in a large number of studies on craniofacial growth (Cheng et al., 2002). Through this method, the spatial relationships between the cranium, vertebrae, mandible, hyoid bone and oropharyngeal space can be easily examined (Machado Júnior \& Crespo, 2010; Kikyo et al.). We carried outdate collection over the entire sample on two occasions, in an attempt to minimize the systematic error. We evaluated whether the data collected by the same examiner at two different times might vary significantly. However, no significant difference was found between the two measurements, confirming intraexaminer consistency of the method.

It is a fact that the clinic test used in the definition of the type of normal or atypical swallowing has its limitations and that the final diagnosis of the type of swallowing has also been based on the experience of each examiner, assessing the involvement of the orbicular muscles in swallowing and other compensatory components. Perfect sealing of the oral cavity, contraction of the masseter muscle which helps the dental occlusion, necessary for swallowing, was observed in normal swallowing. Lip incompetence and effort on the perioral muscles to help swallowing, and, in some cases, spilling of content from the labial commissure and interposition of the tongue to help incompetent lip sealing have been observed in adapted swallowing (Peng et al., 2003, 2004; Bertolini et al.; Malkoc et al.).

This radiographic study evaluated the relationships between known parameters, but these relations were used 
in a novel manner in that they were correlated with normal and abnormal deglutition. In addition to studying a normal group, this study also evaluated patients with atypical deglutition: a quite prevalent clinical condition that can impact orofacial, nutritional, esthetic, and psychosocial development (Cheng et al., 1988).

Since deglutition is a highly complex and coordinated function, it requires activation of many anatomical structures related to the tongue. Insufficient functional stimulation of the stomatognathic system, especially the tongue, might be the main factor in the persistence of childlike deglutition (Peng et al., 2003).

The relationship between craniofacial morphology and extrinsic factors which have an influence on the development of the face has been arousing great interest among researchers (Cayley et al.). Empirically it is believed that in the cases of atypical swallowing there is a tendency to increase the vertical dimensions of the face, although this possible alteration is not considered a cause or a consequence of atypical swallowing. If this fact were an absolute truth and if the position of the hyoid bone were dependant exclusively of the facial type, the hyoid would be closer to the mandibular plane in atypical swallowing in cases of faces with a tendency to vertical growth, a factor which was not observed in our results. Although we did not plan to correlate data of malocclusion and atypical swallowing, we believe that this possibility is real, making this possible relation deserving further studies (Graber et al.).

Studies have investigated the influence of atypical swallowing on the craniofacial pattern and on mandibular morphology, especially of the face vertical dimensions, but there is no consensus among researchers (Cayley et al.; Cheng et al., 2002; Paskay).

Swallowing is a complex and coordinated function, in which a certain number of muscles is involved, specially the muscles of the tongue, which comprehend the intrinsic muscles and extrinsic muscles (Peng et al., 2004).

The extrinsic muscles of the tongue (genioglossus, styloglossus, palatoglossus, hyoglossus and geniohyoid) may possibly have their tonus altered. This possibility has already been observed in studies with ultrasonography (Peng et al., 2003, 2004). These studies suggest that in atypical swallowing the activity of the genioglossus muscle is increased, which would explain the lowered posture of the tongue in atypical swallowing. It also mentions the geniohyoid and mylohyoid was adequate of the distinction of visceral swallowing.
Our unpublished results show that advanced positive correlation of the radiographic position of the hyoid bone to the airway space only in the group of normal swallowing. The observation of this fact leads us to believe that the lower airway in patients with atypical swallowing, possibly causing changes in tongue posture which leads to change in the position of the hyoid bone. Perhaps these changes may be responsible, in part, for deviations face growth.

Craniofacial alterations in children with respiratory obstruction have been studied during the last years. However, the absence of a direct relationship between the cause of respiratory obstruction and its effect on craniofacial growth (Paskay; Adamidis \& Spyropoulos; Cheng et al., 1988; Malkoc et al.; Machado Júnior \& Crespo) has led to considerable controversy in the literature. The most widely accepted theory is that tonsil hypertrophy, which leads to pharyngeal obstruction, causes mouth breathing (Paskay), with the child altering the position of the orofacial muscles and of the mandible. These changes, in turn, influence mastication, deglutition and phonation, and lead to occlusal and skeletal alterations (Paskay; Kikyo et al.).

\section{CONCLUSION}

Our results show that advanced positive correlation of the radiographic position of the hyoid bone to the airway space only in the group of normal swallowing. The lower airway in patients with atypical swallowing, causing changes in tongue posture which leads to change in the position of the hyoid bone.

MACHADO JÚNIOR, A. J. \& CRESPO, A. N. Evaluación cefalométrica del espacio de las vías respiratorias y hueso hioides en niños con deglución atípica: estudio correlacional. Int. J. Morphol., 30(1):341-346, 2012.

RESUMEN: Aunque existe una estrecha relación entre la deglución y la respiración, no se dispone de estudios que relacionen la anatomía radiográfica atípica de deglución del espacio de la vía aérea y su posible correlación con la posición radiológica del hueso hioides. El objetivo fue evaluar la posible correlación de la posición radiológica del hueso hioides y las vías aéreas en radiografías laterales de niños con deglución atípica. Utilizando el análisis cefalométrico sobre telerradiografías laterales, fueron analizadas las correlaciones entre las distancias H-MP (hueso hioides al plano mandibular) y HT (hioides al tubérculo) y el PAS (espacio de la vía aérea) en dos grupos: el grupo experimental con la deglución atípica y el grupo control con deglución normal. Ambos grupos estaban en etapa de dentición mixta. Las variables HT y MP-H tuvieron una correlación estadísticamente significativa con la variable PAS, 0,0286 y 0,0053 respectivamente. Nuestros resultados 
muestran que la correlación positiva de la situación radiológica avanzada del hueso hioides al espacio de las vías respiratorias sólo se observa en el grupo de deglución normal. La vía respiratoria inferior en los pacientes con deglución atípica provoca cambios en la postura de la lengua, lo que conduce a un cambio en la posición del hueso hioides.

PALABRAS CLAVE: Cefalometría; Deglución atípica; Espacio orofaríngeo.

\section{REFERENCES}

Adamidis, I. P. \& Spyropoulos, M. N. The effects of lymphadenoid hypertrophy on the position of the tongue, the mandible and the hyoid bone. Eur. J. Orthod., 5(4):287-94, 1983.

Bertolini, M. M.; Vilhegas, S.; Norato, D. Y. \& Paschoal, J. R. Cephalometric evaluation in children presenting adapted swallowing during mixed dentition. Int. J. Orofacial Myology, 29:29-41, 2003.

Bibby, R. E. The hyoid bone position in mouth breathers and tonguethrusters. Am. J. Orthod., 85(5):431-3, 1984.

Cayley, A. S.; Tindall, A. P.; Sampson, W. J. \& Butcher, A. R. Electropalatographic and cephalometric assessment of myofunctional therapy in open-bite subjects. Aust. Orthod. J., 16(1):23-33, 2000.

Cheng, M. C.; Enlow, D. H.; Papsidero, M.; Broadbent, B. H. Jr.; Oyen, O. \& Sabat, M. Developmental effects of impaired breathing in the face of the growing child. Angle Orthod., 58(4):309-20, 1988.

Cheng, C. F.; Peng, C. L.; Chiou, H. Y. \& Tsai, C. Y. Dentofacial morphology and tongue function during swallowing. Am. J. Orthod. Dentofacial Orthop., 122(5):491-9, 2002.

de Felício, C. M.; Folha, G. A.; Ferreira, C. L. \& Medeiros, A. P. Expanded protocol of orofacial functional evaluation with scores: Validity and reliability. Int. J. Pediatr. Otorhinolaryngol., 74(11):1230-9, 2010.

Graber, T. M.; Rakosi, T. \& Petrovic, A. G. Dentofacial orthopedics with functional appliances. St. Louis, C. V. Mosby Company, 1985. p.139-60.

Kikyo, T.; Saito, M. \& Ishikawa, M. A study comparing ultrasound images of tongue movements between open bite children and normal children in the early mixed dentition period. J. Med. Dent. Sci., 46(3):127-37, 1999.

Machado Júnior, A. J. \& Crespo, A. N. A lateral cephalometric Xray study of selected vertical dimensions in children with atypical deglutition. Int. J. Orofacial Myology, 36:17-26, 2010.
Machado Júnior, A. J. \& Crespo, A. N. Radiographic position of the hyoid bone in children with atypical deglutition. Eur. J. Orthod., 34(1):83-7, 2012a.

Machado Júnior, A. J. \& Crespo, A. N. Cephalometric evaluation of the oropharyngeal space in children with atypical deglutition: radiographic study. Braz. J. Otorhinol., 78(1):120-5, 2012.

Malkoc, S.; Usumez, S.; Nur, M. \& Donaghyd, C. E. Reproducibility of airway dimensions and tongue and hyoid positions on lateral cephalograms. Am. J. Orthod. Dentofacial Orthop., 128(4):513-6, 2005.

Ovsenik, M.; Farcnik, F. M.; Korpar, M. \& Verdenik, I. Follow-up study of functional and morphological malocclusion trait changes from 3 to 12 years of age. Eur. J. Orthod., 29(5):5239, 2007.

Paskay, L. C. Instrumentation and measurement procedures in orofacial myology. Int. J. Orofacial Myology, 32:37-57, 2006.

Peng, C. L.; Jost-Brinkmann, P. G.; Yoshida, N.; Miethke, R. R. \& Lin, C. T. Differential diagnosis between infantile and mature swallowing with ultrasonography. Eur. J. Orthod., 25(5):4516, 2003.

Peng, C. L.; Jost-Brinkmann, P. G.; Yoshida, N.; Chou, H. H. \& Lin, C. T. Comparison of tongue functions between mature and tongue-thrust swallowing--an ultrasound investigation. Am. J. Orthod. Dentofacial Orthop., 125(5):562-70, 2004.

Valera, F. C.; Travitzki, L. V. V.; Mattar, S. E. M.; Matsumoto, M. A. N.; Elias, A. M. \& Anselmo-Lima, W. T. Muscular, functional and orthodontic changes in pre school children with enlarged adenoids and tonsils. Int. J. Pediatr. Otorhinolaryngol., 67(7):761-70, 2003.

Correspondence to:

Almiro J. Machado Júnior

Discipline of Otorhinolaryngology

School of Medical Sciences

Universidade Estadual de Campinas (Unicamp)

Rua Maria Monteiro, 841 ap 11 - Cambuí

CEP 13025-151

Campinas - São Paulo

BRAZIL

Email: almiro@fcm.unicamp.br

Received: 03-08-2011

Accepted: 27-10-2011 